\title{
INVESTIGATION AND OPTIMIZATION OF FORMULATION PARAMETERS FOR SELF- NANOEMULSIFYING DELIVERY SYSTEM OF TWO LIPOPHILIC AND GASTROINTESTINAL LABILE DRUGS USING BOX-BEHNKEN DESIGN
}

\author{
BIMLESH KUMAR ${ }^{1}$, VARUN GARG ${ }^{1}$, AMARJEET SINGH ${ }^{2}$, NARENDRA KUMAR PANDEY ${ }^{1}$, SAURABH SINGH ${ }^{1}$, \\ SAKSHI PANCHAL ${ }^{1}$, INDU MELKANI ${ }^{1}$, RAJI ${ }^{1}$, MANZI AXEL ${ }^{1}$, SOUVIK MOHANTA ${ }^{1}$, JIVAN JYOTI ${ }^{1}$, SANANDA SOM ${ }^{1}$, \\ MONICA GULATI ${ }^{1}$, AMIT BHATIA ${ }^{3}$, PRAKASH T ${ }^{4}$, SACHIN KUMAR SINGH ${ }^{1 *}$
}

${ }^{1}$ School of Pharmaceutical Sciences, Lovely Professional University, Phagwara, Punjab, India. ${ }^{2}$ Pharmacovigilance Scientist, Parexel International Services India Pvt. Ltd, Chandigarh, India. ${ }^{3}$ Department of Pharmaceutical Science and Technology, MRSPTU, Bathinda, India. ${ }^{4}$ Department of Physiology and Pharmacology, Acharya and B.M. Reddy College of Pharmacy, Bengaluru, Karnataka, India.

Email: singhsachin23@gmail.com

Received: 05 April 2018, Revised and Accepted: 09 July 2018

ABSTRACT

Objective: Present research work aims toward codelivery of two hydrophobic drugs, curcumin (CRM) and duloxetine hydrochloride (DXH) through self-nanoemulsifying drug delivery systems (SNEDDS).

Methods: Initially, binary mixture in the ratio of 1:1 was prepared and then loaded into SNEDDS. Box-Behnken design (BBD) was adopted to develop SNEDDS. As per the optimal design, 13 SNEDDS prototypes were prepared. Castor oil, tween-80 and Transcutol $\mathrm{P}^{\circledR}$ were used as oil, surfactant, and cosurfactant, respectively. To $1 \mathrm{~mL}$ of SNEDDS, $30 \mathrm{mg}$ each of CRM and DXH was loaded (CRM-DXH- SNEDDS).

Results: The design revealed that for mean droplet size, polydispersity index (PDI), as well as percentage drug loading, all the three factors, i.e. ratio of oil (a), surfactant (b), and cosurfactant (c) were found to give significant effect. Factor B showed the most significant effect on mean droplet size (y1). In case of PDI (y2), factors B and C exerted maximum influence, whereas, Factor A has shown non-significant effect. For percentage drug loading of drugs ( $\mathrm{y} 3$ and $\mathrm{y} 4$ ), all the three factors were found to have the most significant effect. The optimized batch of CRM-DXH- SNEDDS having composition castor oil, tween-80, and Transcutol ${ }^{\circledR}{ }^{\circledR}$ in the ratio: 2.17:5.22:2.61, revealed that the mean drug loading (\%) of CRM and DXH in an optimized batch of SNEDDS was found to be $87.22 \pm 1.87$ and $92.32 \pm 0.19 \%$, respectively. The mean droplet size, PDI, and zeta potential of formed SNEDDS were observed as $113.14 \pm 1.14 \mathrm{~nm}, 0.20 \pm 0.026$, and $-13.2 \mathrm{mV}$, respectively.

Conclusion: BBD provided optimal formula composition for SNEDDS for obtaining desirable drug loading, emulsion droplet size, and zeta potential.

Keywords: Curcumin, Duloxetine hydrochloride, Binary mixture, Curcumin - duloxetine hydrochloride - self-nanoemulsifying drug delivery systems, Box Behnken design, Castor oil, Transcutol $\mathrm{P}^{\circledR}$, Tween-80.

(c) 2018 The Authors. Published by Innovare Academic Sciences Pvt Ltd. This is an open access article under the CC BY license (http://creativecommons. org/licenses/by/4. 0/) DOI: http://dx.doi.org/10.22159/ajpcr.2018.v11s2.28585

\section{INTRODUCTION}

Duloxetine hydrochloride (DXH), an antidepressant possesses a significant pain-relieving effect. It is the first prescription drug that was approved by the Food and Drug Administration for treatment of painful diabetic neuropathy $[1,2]$. It is reported to exert its action through inhibition of both serotonin (5-HT) and norepinephrine (NE) reuptake [3-5]. These serotonin/noradrenaline reuptake inhibitors are also used clinically as a treatment modality for neuropathic pain [4].

Curcumin (CRM) (Curcuma longa) is well-established biologically active natural material derived from turmeric plants [6]. CRM inhibits mitogenactivated protein kinases [7] and has been reported for an antioxidant, anti-inflammatory, immunomodulatory, cancer chemopreventive, antiulcer, and neuroprotective activities [8-14].

Therapeutic modalities provide only partial relief, and there is no single treatment that works for all conditions of neuropathy. Hence, there is an ample scope to develop new medicine, particularly, a combination of one of synthetic and second of plant origin. Therefore, an attempt has been done to coadminister DXH and CRM for effective treatment of neuropathic pain using a suitable delivery system.

The major impediments that restrict the choice of delivery system for concomitant delivery of those two drugs include the poor aqueous solubility of both the drugs and degradation of DXH in the harsh environment of the stomach $[15,16]$. This ultimately leads to poor oral bioavailability of drugs when administered orally. A number of initiatives have been taken in the past to develop oral formulations of DXH and CRM [5,17-19]; however, they were not found to be very successful clinically.

Self-nanoemulsifying drug delivery systems (SNEDDSs) have been reported to overcome such challenges. They have been successfully reported delivering poorly soluble drugs as well as drugs that get degraded through oral route $[20,21]$. Mechanisms that are involved in the absorption of oils/lipids include passive diffusion, or pinocytosis, or absorption through lymphatic system [22].

Combination of CRM and DXH, loaded as SNEDDS, is expected to increase drug solubilization, increase in surface area of droplets due to nanometer size range, surface induced permeability that could allow very large distribution of the drug in the GIT, and protection against enzymatic/acidic degradation [23,24]. Based on this hypothesis, an attempt has been made to formulate SNEDDS for CRM-DXH binary mixture. The formulation was developed using the design of experiments (DoE). Box-Behnken design (BBD) was used to investigate the formulation variables that could affect droplet size, zeta potential, and percentage drug loading of CRM and DXH. BBD is a systematic 
approach that helps researchers to understand the process variables that could significantly affect the product quality. In this way, the nonsignificant variables could be eliminated.

\section{MATERIALS AND METHODS}

\section{Materials used}

DXH was gifted by Sun Pharma, Mumbai, India. CRM was procured from Central Drug House (CDH) (P) Ltd from Mumbai (India). Polyethylene glycol (PEG) 200 and 600, propylene glycol, olive oil, castor oil, eucalyptus oil, oleic acid, polyvinyl alcohol, tween 60 and 80, span 20 and 80, and ethanol were procured from CDH, India. Transcutol $\mathrm{P}^{\circledR}$ was received as gift sample from M/s Gattefosse, India. All other chemicals used were of analytical grade and purchased from local chemical agencies.

\section{Experimental}

\section{Solubility studies}

The solubility of CRM and DXH in various oils, surfactants, and cosurfactants were determined using shake flask method [25-27]. The solubility studies have been performed in oils (olive oil, eucalyptus oil, cottonseed oil, sunflower oil, castor oil, peanut oil, and oleic acid), surfactants (tween 60 and 80, span 20 and 80, and PEG 200 and 600), and cosurfactant (Transcutol $\mathrm{P}^{\circledR}$ and ethanol) to find suitable oil, surfactant, and cosurfactant for the formulation of SNEDDS. To $1 \mathrm{~mL}$ of each oil, surfactant, and cosurfactants, $30 \mathrm{mg}$ each of DXH and CRM was added, and the mixtures were vortexes for 2 min at regular interval up to $48 \mathrm{~h}$. The solutions were centrifuged at $3500 \mathrm{rpm}$ for $15 \mathrm{~min}$, and the supernatants were collected. Oily solutions were diluted with n-hexane whereas surfactant and cosurfactant solutions were diluted with distilled water for analysis. Samples were analyzed using high-performance liquid chromatography (HPLC) method that has been already developed and validated for the estimation of CRM and DXH [28].

\section{Screening of surfactants for emulsifying ability and construction} of ternary phase diagrams

Emulsification ability of various surfactants was screened [25]. Ternary mixtures were prepared by mixing oil, surfactant, and cosurfactant. Various combinations of surfactant, cosurfactant, and oil were used, and their concentrations were varied in each formulation. Phase diagrams were constructed to identify good self-emulsifying region. All studies were carried out in triplicate, with similar observations being made between repeats. The self-emulsifying performance was visually assessed after dilution using purified water. To find out the SNEDDS region, 324 prototypes of SNEDDS were formulated by varying the composition of oil, surfactants, and cosurfactants. The ratio of oil and $\mathrm{S}_{\text {mix }}$ (mixture of surfactant and cosurfactant) was kept as 1:9, 2:8, 3:7, $4: 6,5: 5,6: 4,7: 3,8: 2$, and 9:1, respectively. In the present study, $\mathrm{S}_{\text {mix }}$ was kept in the ratio of $1: 1,1: 2$, and 2:1, respectively. Three different oils (castor oil, olive oil, and sunflower oil), two different surfactants (tween-80 and PEG-200), and two different cosurfactants (Transcutol $\mathrm{P}^{\circledR}$ and ethanol) have been used.

Hence, for each oil 27 batches each were prepared using Transcutol $\mathrm{P}^{\circledR}$ and ethanol as cosurfactant, respectively, while keeping Tween-80 as a surfactant. Similarly, 27 batches were prepared for each oil using Transcutol $\mathrm{P}^{\circledR}$ and ethanol as cosurfactant, respectively, keeping PEG200 as a surfactant. Summarizing the above statement for each oil, 108 batches of SNEDDS prototypes were prepared. The mixture was vortexed for 15 min using vortex mixer (CM 101 CYCLO MIXER, REMI, India). Further, the prepared isotropic mixtures were diluted to $500 \mathrm{~mL}$ of double distilled water and stirred at $500 \mathrm{rpm}$ at a temperature of $37 \pm 5^{\circ} \mathrm{C}$. The ease of formation of the emulsion was also noted. The resulting emulsions were allowed to stand for $2 \mathrm{~h}$ and then observed visually for relative turbidity.

\section{DOE for selection of optimized batch for CRM-DXH- SNEDDS}

From the ternary phase diagram, nanoemulsion region was selected. The results revealed that formulations wherein castor oil were used as lipid phase and $\mathrm{S}_{\text {mix }}$ (ratio of tween 80 and Transcutol $\mathrm{P}^{\circledR}$ ) in ratios of 1:1 $\left(\mathrm{F}_{301-303}\right), 2: 1\left(\mathrm{~F}_{311-313}\right)$, and 1:2 $\left(\mathrm{F}_{321-323}\right)$ have shown the largest nanoemulsion area. Hence, these three excipients have been selected for further formulation development. A set of experiments with BBD was adopted to develop the SNEDDS of CRM-DXH binary mixture. The amount of CRM and DXH was kept constant, type of oil, and type of surfactant and cosurfactant were kept constant for all the experiments and ratio of castor oil, tween-80, and Transcutol $P^{\circledR}$ was varied.

All these factors were operated at three levels $(+1,0$, and -1$)$. DesignExpert ${ }^{\circledR}$ Dx 9.0.1 software was used to conduct the study. A total of 13 experiments were designed by the software. Experiments were run in random order to increase the predictability of the model. Table 1 shows the independent factors and their design level used in this study. Table 2 lists out the formula composition of SNEDDS with respect to ratios as mentioned in DOE. All the formulated batches were subjected for analysis of emulsion droplet size analysis, percentage drug loading, and polydispersity index (PDI).

\section{Characterization of prepared SNEDDS Calculation of drug loading}

As per the design mentioned in DOE, SNEDDS was prepared by adding CRM and DXH (in the ratio of 1:1) equivalent to $30 \mathrm{mg}$ to each batch in $1 \mathrm{~mL}$ mixture of castor oil, tween-80, and Transcutol $\mathrm{P}^{\circledR}$ (Table 3). These was place in a vortex mixer for vortexing (CM 101 CYCLO MIXER, REMI, India) for $15 \mathrm{~min}$ and then added to $500 \mathrm{~mL}$ of double distilled water kept in a $1000 \mathrm{~mL}$ glass beaker. The diluted mixture was stirred at $500 \mathrm{rpm}$ at a temperature of $37^{\circ} \mathrm{C}$. Sample $(5 \mathrm{~mL})$ was withdrawn and filtered through $0.2 \mu \mathrm{m}$ membrane filter (Millipore, Germany) and centrifuged at $10000 \mathrm{rpm}$ for $15 \mathrm{~min}$. The collected supernatant was analyzed using HPLC [28]. The percentage drug loading was calculated as per equation 1 .

$\%$ Drug loading $=\frac{\text { Area of test drug present in SNEDDS }}{\text { Absorbance of known standard }} \times 100$

\section{Particles size and zeta potential}

Photon correlation spectroscopy using Malvern zeta sizer nano ZS90 (Malvern Instruments Ltd., UK) with a $50 \mathrm{mV}$ laser at a fixed angle of $90^{\circ}$ was used to measure measurement of droplet size, PDI, and zeta potential. Measurements were carried out at $25^{\circ} \mathrm{C}$ using disposable

Table 1: Variables for Box-Behnken study for CRM-DXH- SNEDDS

\begin{tabular}{lllll}
\hline Independent factors & & \multicolumn{2}{l}{ Design level } \\
\cline { 1 - 1 } Uncoded & & Coded & Uncoded & Coded \\
\hline Ratio of oil in SNEDDS & $\mathrm{A}$ & 0.10 & \\
& & 0.20 & -1 \\
Ratio of surfactant in SNEDDS & $\mathrm{B}$ & 0.30 & $0+1$ \\
& & 0.20 & \\
Ratio of cosurfactant in SNEDDS & $\mathrm{C}$ & 0.40 & -1 \\
& & 0.60 & $0+1$ \\
& & 0.40 & -1 \\
& & 0.60 & $0+1$ \\
\hline
\end{tabular}

SNEDDSs: Self-nanoemulsifying drug delivery systems

Table 2: Formula composition for CRM-DXH-SNEDDS

\begin{tabular}{ll}
\hline Ingredients & Quantity/batch (g) \\
\hline Binary (CRM: DXH) & 0.03 each $(1: 1)$ \\
Castor oil & $0.096-0.288$ \\
Tween 80 & $0.214-0.642$ \\
Transcutol P & $0.2964-0.5928$ \\
\hline
\end{tabular}

SNEDDSs: Self-nanoemulsifying drug delivery systems 
Table 3: Factor level and response data for BBD for CRM-DXH- SNEDDS

\begin{tabular}{|c|c|c|c|c|c|c|c|}
\hline Run & $\begin{array}{l}\text { Factor } 1 \\
\text { A: Castor oil } \\
(\mu \mathrm{L})\end{array}$ & $\begin{array}{l}\text { Factor } 2 \\
\text { B: Tween } 80 \\
(\mu L)\end{array}$ & $\begin{array}{l}\text { Factor } 3 \\
\text { C: Transcutol P } \\
(\mu L)\end{array}$ & $\begin{array}{l}\text { Mean droplet } \\
\text { size }(\mathrm{nm})\end{array}$ & PDI & $\begin{array}{l}\text { Drug loading of } \\
\text { CRM (\%) }\end{array}$ & $\begin{array}{l}\text { Drug loading of } \\
\text { DXH (\%) }\end{array}$ \\
\hline 1 & 200 & 400 & 450 & 161.2 & 0.113 & 74.6 & 99.1 \\
\hline 2 & 100 & 400 & 300 & 235.9 & 0.403 & 89.4 & 100 \\
\hline 3 & 100 & 400 & 600 & 225 & 0.722 & 92.6 & 100 \\
\hline 4 & 100 & 600 & 450 & 221 & 0.725 & 92.5 & 91.3 \\
\hline 5 & 300 & 200 & 450 & 382.9 & 0.577 & 59.8 & 54 \\
\hline 7 & 200 & 200 & 300 & 251.9 & 0.468 & 74.9 & 51.6 \\
\hline 8 & 200 & 600 & 300 & 120.8 & 0.269 & 100 & 100 \\
\hline 9 & 300 & 600 & 450 & 122.6 & 0.26 & 99.1 & 80.7 \\
\hline 10 & 300 & 400 & 300 & 203.8 & 0.285 & 89.5 & 99.8 \\
\hline 11 & 200 & 600 & 600 & 98.03 & 0.422 & 84.3 & 100 \\
\hline 12 & 300 & 400 & 600 & 159.5 & 0.172 & 91.3 & 68.2 \\
\hline 13 & 100 & 200 & 450 & 260.2 & 0.404 & 73.8 & 100 \\
\hline
\end{tabular}

BBD: Box-Behnken design, SNEDDSs: Self-nanoemulsifying drug delivery systems, DHX: Duloxetine hydrochloride, CRM: Curcumin, PDI: Polydispersity index

polystyrene cells and disposable plain folded capillary cells after dilution. L-SNEDDS/S-SNEDDS sample $(100 \mu \mathrm{L})$ was diluted with $100 \mathrm{~mL}$ double distilled water. Each run underwent 12 sub-runs for a period of $2 \mathrm{~min}$. Each study was repeated in triplicate to record the mean data $[27,29]$.

\section{Statistical analysis}

Statistical analysis of obtained data was carried out either by analysis of variance (ANOVA) or Tukey's multiple comparison tests. The dissolution profile was compared using model-independent analysis ( $\mathrm{F}_{2}$ comparison) as discussed in Shah et al. 1998 [30].

\section{RESULTS AND DISCUSSIONS}

Solubility studies of CRM and DXH in oils, surfactants, and cosurfactants

The observed results of solubility study indicated in Table 4 that the solubility of CRM in oil was in the following order:

Sunflower oil $>$ eucalyptus oil $>$ peanut oil $>$ olive oil $>$ castor oil $>$ cottonseed oil > oleic acid

Among surfactants the solubility of CRM was found to be:

Tween-80 > PEG200 > PEG600 > Tween-60 > Span-20 > Span-80

Among cosurfactant it was found to be:

Ethanol > Transcutol $\mathrm{P}^{\circledR}$

Similarly, solubility of DXH in various oils was tested, and order of solubility was:

Eucalyptus oil $>$ sunflower oil $>$ castor oil $>$ cottonseed oil $>$ olive oil $>$ peanut oil >

oleic acid

Solubility of DXH in surfactant was as follows:

PEG-600 > PEG-200 > Tween-80 > Tween-60 > Span-20 > Span-80

Solubility of DXH in cosurfactant was in the following order:

Ethanol > Transcutol $\mathrm{P}^{\circledR}$

Since, an optimum solubility of both the drugs was found in sunflower oil, olive oil, and castor oil; these were selected as oils for preparation of ternary phase diagram. Among, surfactants and solubility were found to be good in tween-80 and PEG-200 and among cosurfactants, in Transcutol $\mathrm{P}^{\circledR}$, and ethanol.

Screening of oils, surfactants, and cosurfactants for emulsification ability and construction of ternary phase diagram

A series of SEDDS were prepared and were visually observed for their self-emulsifying properties. The formed emulsions were analyzed as SNEDDS, SMEDDS, and normal emulsion. In the presence of CRM-DXH, pseudoternary phase diagram was constructed for the identification of self-emulsifying region and to optimize the concentration of oil,
Table 4: Solubility studies of CRM and DXH in different oils, surfactant, and cosurfactant

\begin{tabular}{lll}
\hline Components & CRM & DXH \\
\hline Olive oil & $3.95 \pm 0.03$ & $6.13 \pm 0.08$ \\
Eucalyptus oil & $5.15 \pm 0.015$ & $48.11 \pm 0.17$ \\
Cottonseed oil & $3.2 \pm 0.015$ & $6.82 \pm 0.15$ \\
Sunflower oil & $5.87 \pm 0.005$ & $11.33 \pm 0.08$ \\
Castor oil & $3.54 \pm 0.02$ & $7.27 \pm 0.05$ \\
Peanut oil & $4.51 \pm 0.02$ & $2.04 \pm 0.04$ \\
Oleic oil & $2.79 \pm 0.005$ & $1.43 \pm 0.02$ \\
PEG200 & $0.89 \pm 0.01$ & $69.1 \pm 0.02$ \\
PEG600 & $0.52 \pm 0.01$ & $75.7 \pm 0.01$ \\
Tween-60 & $0.18 \pm 0.05$ & $13.12 \pm 0.02$ \\
Tween-80 & $3.36 \pm 0.01$ & $27.23 \pm 0.22$ \\
Span20 & $0.1 \pm 0.01$ & $10.23 \pm 0.03$ \\
Span80 & $0.08 \pm 0.001$ & $5.42 \pm 0.8$ \\
Transcutol P & $8.43 \pm 0.02$ & $60.89 \pm 1.54$ \\
Ethanol & $118.9 \pm 1.24$ & $73.47 \pm 0.72$ \\
\hline
\end{tabular}

DHX: Duloxetine hydrochloride, CRM: Curcumin

surfactant, and cosurfactant in the formulation of SEDDS. Ternary phase diagram for formulations $F_{1}-F_{29}$ was prepared, wherein various ratios of olive oil, PEG-200, and Transcutol $\mathrm{P}^{\circledR}$ were used. For formulations $\mathrm{F}_{31}-\mathrm{F}_{59}$, the ternary phase diagram includes various ratios of olive oil, PEG-200, and ethanol. Formulations $\mathrm{F}_{61}$ to $\mathrm{F}_{89}$, wherein various ratios of olive oil, tween-80, and Transcutol $\mathrm{P}^{\circledR}$ and for formulations F91-119, various ratios of olive oil, tween-80, and ethanol were used for the preparation of ternary phase diagram. The ternary phase diagram for formulations $\mathrm{F}_{121}-\mathrm{F}_{149}$, various ratios of sunflower oil, PEG-200, and Transcutol $\mathrm{P}^{\circledR}$ were used, and for formulations $\mathrm{F}_{151}-\mathrm{F}_{179}$, various ratios of sunflower oil, PEG-200, and ethanol were used. The ternary phase diagram for formulations $\mathrm{F}_{181}-\mathrm{F}_{209}$, various ratios of sunflower oil, tween-80, and Transcutol $\mathrm{P}^{\circledR}$ were used, and for formulations, $\mathrm{F}_{211}$ to $\mathrm{F}_{239}$, various ratios of sunflower oil, tween-80, and ethanol were used. The ternary phase diagram for formulations $\mathrm{F}_{241}-\mathrm{F}_{269}$, various ratios of castor oil, PEG-200, and Transcutol $\mathrm{P}^{\circledR}$ were used, and for formulations $\mathrm{F}_{271}$ to $\mathrm{F}_{299}$, various ratios of castor oil, PEG-200, and ethanol were used. The ternary phase diagram for formulations $\mathrm{F}_{301}-\mathrm{F}_{329}$, various ratios of castor oil, tween-80, and Transcutol $\mathrm{P}^{\circledR}$ were used, and for formulations $\mathrm{F}_{331}$ to $\mathrm{F}_{359}$, various ratios of castor oil, tween-80, and ethanol were used. It was observed that only 27 formulations $\mathrm{F}_{71}, \mathrm{~F}_{81}, \mathrm{~F}_{91}, \mathrm{~F}_{101}, \mathrm{~F}_{181}, \mathrm{~F}_{191}, \mathrm{~F}_{192}, \mathrm{~F}_{201}, \mathrm{~F}_{202}, \mathrm{~F}_{211}, \mathrm{~F}_{221}$, $\mathrm{F}_{222}, \mathrm{~F}_{241}, \mathrm{~F}_{242}, \mathrm{~F}_{271}, \mathrm{~F}_{272}, \mathrm{~F}_{301}, \mathrm{~F}_{302}, \mathrm{~F}_{303}, \mathrm{~F}_{311}, \mathrm{~F}_{312}, \mathrm{~F}_{313}, \mathrm{~F}_{321}, \mathrm{~F}_{322}, \mathrm{~F}_{323}, \mathrm{~F}_{331}$, and $\mathrm{F}_{351}$ have shown very good emulsification region with transparency after dilution in water. It is important to note here that formulations wherein tween-80 were used as a surfactant and Transcutol $\mathrm{P}^{\circledR}$ as cosurfactant in varying ratios of 1:1 (F301-303), 2:1 (F311-313), and 1:2 (F321-323), have shown the largest nanoemulsion area. Consequently, for further studies, these formulations have been selected. 
Experimental design using Box-Behnken

The formula composition of CRM-DXH-SNEDDS as per DoE is shown in Table 3. A total of 13 experiments were designed by the software with two center points. Experiments were run in random order to increase the predictability of model.

The responses obtained for this study were well modeled by a linear function of independent variables; hence, first order polynomial was used for approximating the function as shown in equation 1 (Eq. 1).

$y=\beta+\beta_{1} x 1+\beta_{2 x} 2+\beta_{3 x} 3+\beta_{4 x} 4+€$

Where, $€$ represents noise or error, $\mathrm{X}$ represents independent variable, Y represents response, and $\beta$ represents coefficient [31].

The values of responses y1 (mean droplet size), y2 (PDI), y3 (\% drug loading of CRM), and y4 (\% drug loading of DXH) ranged from 98.03 to $178 \mathrm{~nm}, 0.113$ to $0.725,48.40$ to $100 \%$, and 51.6 to $100 \%$, respectively. The ratio of maximum to minimum for the responses $\mathrm{y} 1, \mathrm{y} 2, \mathrm{y} 3$, and $\mathrm{y} 4$ is

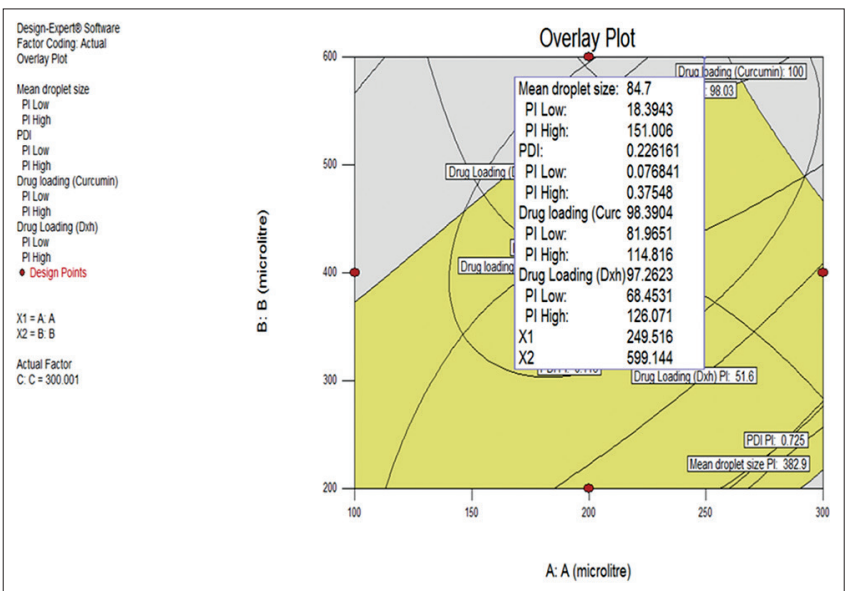

Fig. 1: Overlay plot showing the optimized batch of selfnanoemulsifying drug delivery systems
$3.90,6.41,2.07$, and 1.94, respectively; therefore, power transformation was not applied to the obtained values. ANOVA was applied to determine the significance and the magnitude of the effects of the main variables and their interactions. The regression model obtained was used to generate the counterplots for independent factors. The ANOVA table confirmed the adequacy of the model (i.e. $\mathrm{F}<0.05$ ) as shown in Table 5 . It also identified the significant factors that affect the responses y1-y3 of SNEDDS.

"A perturbation graph was plotted to find those factors that have affected the response the most. A steep slope or curvature in a factor showed that the response was sensitive to that factor. A relatively flat line showed insensitivity to change in that particular factor" [29]. For mean droplet size (Fig. 2a) and PDI (Fig. 2b) all the three factors, i.e. ratio of oil (A), surfactant (B), and cosurfactant (C) were identified as significant model terms (Fig. 2a and b). However, factor A has shown the most significant effect on mean droplet size. For percentage drug loading of CRM, ratio of surfactant (B) was found to decipher the most significant effect (Fig. 2c). Factors $A$ and $C$ have also shown their effect on percentage drug loading of CRM but these not so significant as that of factor B. In case of percentage drug loading of DXH, factors A (ratio of oil) and B (ratio of surfactant) were found to have a significant effect (Fig. 2d).

The final mathematical model in terms of coded factors as determined by design expert software is shown below in equations (2-4) for response y1-y4, respectively.

Table 5: Summary of ANOVA of Box-Behnken screening design for CRM-DXH- SNEDDS

\begin{tabular}{llll}
\hline \multirow{2}{*}{ Response variables } & \multicolumn{3}{l}{ Regression parameters } \\
\cline { 2 - 4 } & $\mathbf{R}^{\mathbf{2}}$ & $\mathbf{F}_{\text {cal }}$ & P value \\
\hline Mean droplet size $\left(\mathrm{Y}_{1}\right)$ & 0.938 & 11.94 & 0.0018 \\
PDI $\left(\mathrm{Y}_{2}\right)$ & 0.966 & 21.74 & 0.0003 \\
\% Drug loading of CRM $\left(\mathrm{Y}_{3}\right)$ & 0.907 & 7.47 & 0.0073 \\
\% Drug loading of DXH $\left(\mathrm{Y}_{4}\right)$ & 0.500 & 3.70 & 0.0401 \\
\hline
\end{tabular}

SNEDDSs: Self-nanoemulsifying drug delivery systems, DHX: Duloxetine hydrochloride, CRM: Curcumin, ANOVA: Analysis of variance, PDI: Polydispersity index

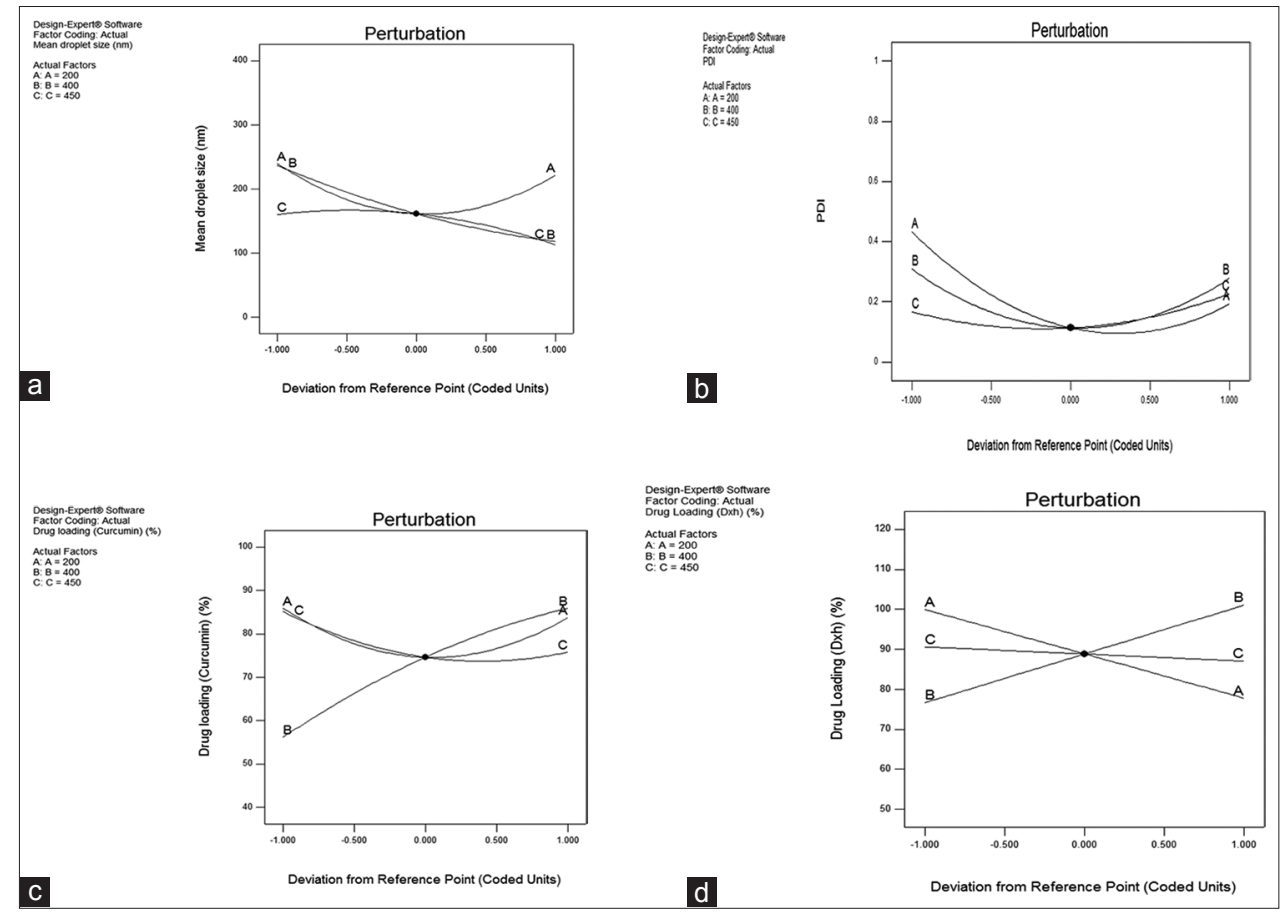

Fig. 2: Perturbation plot showing the influence of individual factors on mean droplet size (y1) (a), polydispersity index (y2) (b), and percentage drug loading of curcumin (1), and percentage drug loading of duloxetine hydrochloride (d) 


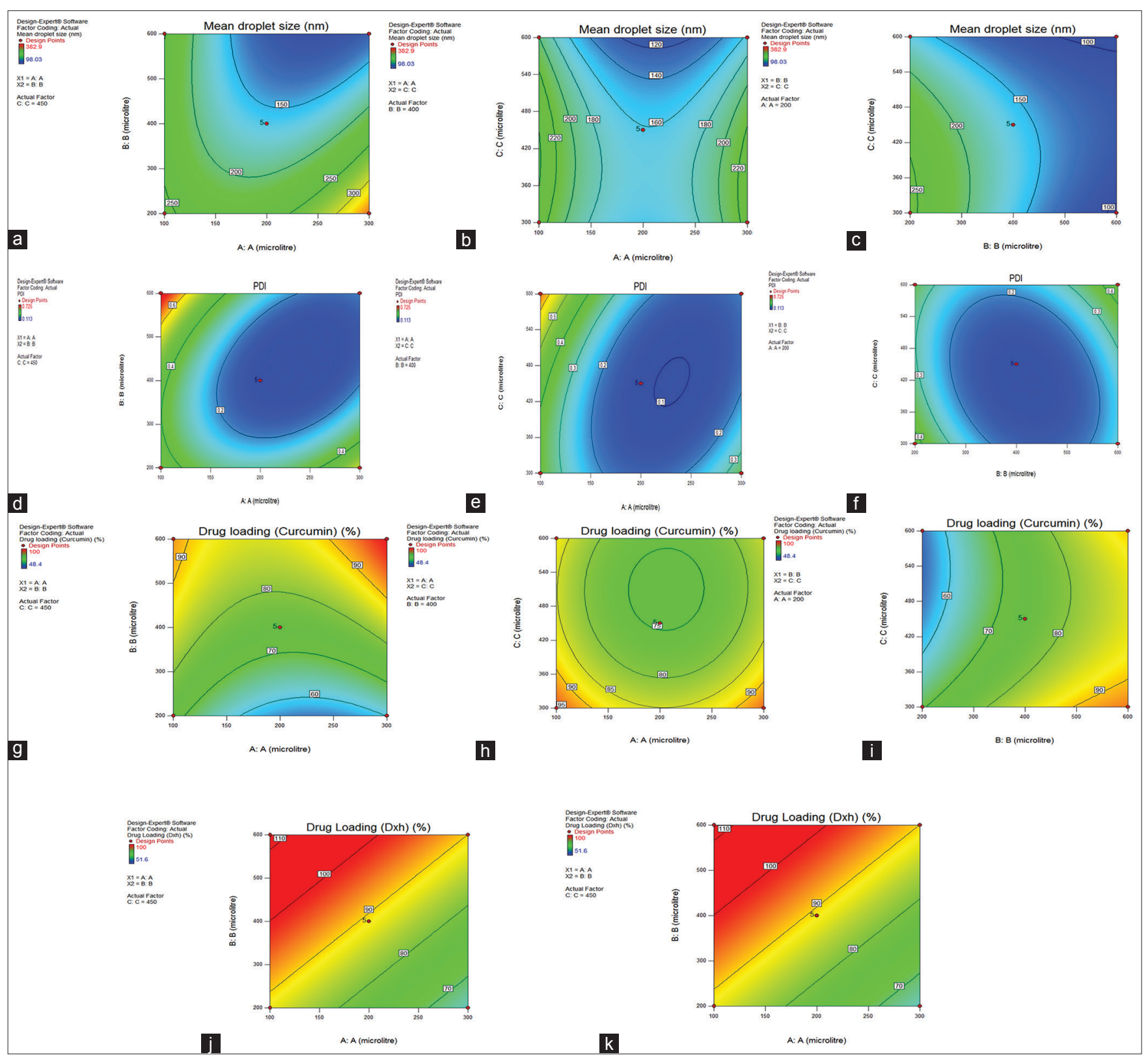

Fig. 3: Contour plot showing the effect of Factor $A$ and $B$ on response $Y_{1}$ at fixed levels of Factor $C$ (2a); Factors $A$ and $C$ on response $Y_{1}$ at fixed levels of Factor $B(2 b)$; Factors $B$ and $C$ on response $Y_{1}$ at fixed levels of Factor A (2c); Factors $A$ and $B$ on response $Y_{2}$ at fixed levels of Factor C (2d.); Factors $A$ and $C$ on response $Y_{2}$ at fixed levels of Factor B (2e); Factors B and C on response $Y_{2}$ at fixed levels of Factor $A$ (2f); Factors $A$ and $B$ on response $Y_{3}$ at fixed levels of Factor $C$ (2g.); Factors $A$ and $C$ on response $Y_{3}$ at fixed levels of Factor B (2h.); Factors $B$ and $C$ on response $Y_{3}$ at fixed levels of Factor $A\left(2 i\right.$.); Factors $A$ and $B$ on response $Y_{4}$ at fixed levels of Factor $C$ ( $2 j$.); Factors $A$ and $C$ on response $\mathrm{Y}_{4}$ at fixed levels of Factor $B$

Mean droplet size $(\mathrm{y} 1)=+161.20-9.16 \times \mathrm{A}-59.10 \times \mathrm{B}-23.71 \times \mathrm{C}-55.28$ $\times \mathrm{AB}-8.35 \times \mathrm{AC}+22.23 \times \mathrm{BC}+69.40 \times \mathrm{A}^{2}+16.08 \times \mathrm{B}^{2}-24.55 \times \mathrm{C}^{2}$

PDI $(\mathrm{y} 2)=+0.11-0.12 \times \mathrm{A}-0.015 \times \mathrm{B}+0.030 \times \mathrm{C}-0.16 \times \mathrm{AB}-0.11 \times$ $\mathrm{AC}+0.068 \times \mathrm{BC}+0.20 \mathrm{~A}^{2}+0.18 \times \mathrm{B}^{2}+0.084 \times \mathrm{C}^{2}$

$\%$ Drug loading of CRM $(\mathrm{y} 3)=+74.60-1.08 \times \mathrm{A}+14.87 \times \mathrm{B}-4.65 \times$ $\mathrm{C}+5.15 \times \mathrm{AB}-0.35 \mathrm{AC}+2.70 \times \mathrm{BC}+10.25 \times \mathrm{A}^{2}-3.55 \times \mathrm{B}^{2}+5.85 \times \mathrm{C}^{2}$ $\%$ Drug loading of DXH $(\mathrm{y} 4)=+88.82-11.08 \times \mathrm{A}+12.19 \times \mathrm{B}-1.79 \times \mathrm{C}$

Positive sign represented a synergistic effect, while a negative sign indicated an antagonistic effect. In case of y1, negative coefficients of A, $\mathrm{B}$, and $\mathrm{C}$ of the model referred to decreased mean droplet size at a higher level of oil, surfactant, and cosurfactant, respectively. A decrease in mean droplet size of the formulation was observed with an increase in surfactant due to reduced interfacial tension and solubilization of oil. Furthermore, mixtures of surfactant and cosurfactant formed complete film around dispersed droplets and maintain droplet stability by strengthening their interfacial film. In addition, the surfactants are used to partition at a higher level into oil-water interface[29]. Response y2 referred to decrease in the PDI of the SNEDDS which represents the negative coefficients of A and B. Whereas positive coefficient of $\mathrm{C}$ indicated an increase in PDI with the increase in ratio of cosurfactant. In case of percentage drug loading of CRM (y3) and DXH (y4), negative coefficient of A and C indicated that with increase in the ratio of oil and cosurfactant, decrease in percentage drug loading of both the drugs was observed, whereas it increased with increase in the amount of surfactant (B). 
Based on ANOVA and perturbation plot factors A, B, and C were most ideal for generating 2D contour plots for response y1 to y4. Factor A was focused for generating 2D contour plot for response y2. Whereas, for Factor y4, Factors A and B were considered for generation of 2D contour plots.

Fig. 3a shows the effect of Factor A and B on response y1 at fixed levels of factor C. Fig. 3b shows the effect of Factors A and C on response y1 at fixed levels of factor B. Fig. 3c shows the effect of Factors B and C on response $\mathrm{y} 1$ at fixed levels of Factor A. Fig. 3a-c shows that at a higher level of Factor A, B, and C, the mean droplet size was decreasing. This revealed that all the three factors have significantly contributed to decreasing the droplet size for the formulation of SNEDDS. From Fig. 3b and c, it is very pertinent that with the increase of the ratio of surfactant (B) and cosurfactant (C) in the formulation the maximum decrease in mean droplet size was observed. This could be attributed to the fact that the decrease in surface tension could be the main factor that would have caused the decrease in droplet size.

Fig. 3d shows the effect of Factor A and B on response y 2 at fixed levels of Factor C. Fig. 3e shows the effect of Factors A and C on response y2 on fixed levels of Factor B. Fig. 3f shows the effect of Factors B and C on response y2 at fixed levels of Factor A. Fig. $3 \mathrm{~d}$ shows that with the increase in Factors A and B a decrease in PDI was observed. Whereas, Fig. 3e revealed that PDI decreased with an increase in A and increased with an increase in C. Similar types of results were observed in case of Fig. 3f, wherein, PDI decreased with an increase in A and increased with an increase in $\mathrm{C}$

Fig. 3g shows the effect of Factor A and B on response y3 at fixed levels of Factor C. Fig. 3h shows the effect of Factors $A$ and $C$ on response y3 on fixed levels of Factor B. Fig. 3i shows the effect of Factors B and $\mathrm{C}$ on response y3 at fixed levels of Factor A. Fig. 3g shows that with the increase in Factor A, decrease in percentage drug loading of CRM was observed, whereas, with increase in Factor B, the percentage drug loading of CRM increased.

In Fig. 3h, a decrease in percentage drug loading of CRM was observed with an increase in Factors A and C. Similar types of results were observed in case of Fig. 3i, wherein, percentage drug loading of CRM decreased with an increase in $\mathrm{C}$ and increased with an increase in $\mathrm{B}$. In Fig. 3j, the effect of Factor A and B on response $\mathrm{y} 4$ at fixed levels of Factor C. In Fig. 3k, the effect of Factors A and C on response y 4 on fixed levels of Factor B. From Fig. 3j, it was observed that percentage drug loading of DXH decreased with increase in Factor A and increased with the increase in Factor B, whereas percentage drug loading of CRM was decreased with increase in Factor C (Fig. 3k).

Optimization of formulation and processing parameters for CRMDXH SNEDDS using graphical optimization method

Optimization of CRM-DXH-SNEDDS was performed to find the levels of Factors A-C which gave mean droplet size y1 of 18.39-151 nm range, y2 in 0.077-0.375 range, y3 in 81.97-114.82\% range, and y4 in 68.45$126.07 \%$ range. Under this model predicted y1-y 4 in required range at $\mathrm{A}, \mathrm{B}$, and $\mathrm{C}$ values of $217.23 \mu \mathrm{L}$ (volume of oil), $521.6 \mu \mathrm{L}$ (volume of surfactant), and $261.17 \mu \mathrm{L}$ (volume of cosurfactant), respectively, for $1000 \mu \mathrm{L}(1 \mathrm{~mL})$ of CRM-DXH-SNEDDS. Using these values of factors, three different batches of SNEDDS were prepared. Fig. 1 represents overlay plot showing the optimized batch of SNEDDS. The optimal ratio for the formulation for oil, surfactant, and cosurfactant was 2.17:5.22:2.61, respectively. The zeta potential of optimized batch was $-13.2 \mathrm{mV}$ and droplet size of $113.14 \pm 1.14 \mathrm{~nm}$. The drug loading (\%) was $87.22 \pm 1.87 \%$ for CRM and $92.32 \pm 0.19$ for DXH in the optimized formulation.

\section{CONCLUSION}

Present study deciphers successful optimization for the formulation of SNEDDS for oral delivery of two poorly soluble and gastric labile drugs, $\mathrm{CRM}$ and DXH, present in the form of a binary mixture. Castor oil, tween
80 , and Transcutol $\mathrm{P}^{\circledR}$ as the components and BBD were as a statistical tool used to optimize the formulation variables.

\section{REFERENCES}

1. Finnerup NB, Otto M, McQuay H, Jensen TS, Sindrup SH. Algorithm for neuropathic pain treatment: An evidence based proposal. Pain 2005; 118:289-305

2. Kuhad A, Bishnoi M, Chopra K. Anti-nociceptive effect of duloxetine in mouse model of diabetic neuropathic pain. Indian J Exp Biol 2009;47:193-7.

3. Xu B, Descalzi G, Ye HR, Zhuo M, Wang YW. Translational investigation and treatment of neuropathic pain. Mol Pain 2012;8:15.

4. Katsuyama S, Aso H, Otowa A, Yagi T, Kishikawa Y, Komatsu T, et al. Antinociceptive effects of the serotonin and noradrenaline reuptake inhibitors milnacipran and duloxetine on vincristine-induced neuropathic pain model in mice. ISRN Pain 2014;2014:915464.

5. Mannari C, Origlia N, Scatena A, Del Debbio A, Catena M, Dell'Agnello G, et al. BDNF level in the rat prefrontal cortex increases following chronic but not acute treatment with duloxetine, a dual acting inhibitor of noradrenaline and serotonin re-uptake. Cell Mol Neurobiol 2008;28:457-68

6. Geetha RV, Gokul G. Effect of Curcuma longa extract on biofilm formation by Streptococcus mutans. Asian J Pharm Clin Res 2017;2:186-7.

7. Jeon Y, Kim CE, Jung D, Kwak K, Park S, Lim D, et al. Curcumin could prevent the development of chronic neuropathic pain in rats with peripheral nerve injury. Curr Ther Res 2013;74:1-4.

8. Vyas A, Dandawate P, Padhye S, Ahmad A, Sarkar F. Perspectives on new synthetic curcumin analogs and their potential anticancer properties. Curr Pharm Des 2013;19:2047-69.

9. Aggarwal BB, Harikumar KB. Potential therapeutic effects of curcumin, the anti-inflammatory agent, against neurodegenerative, cardiovascular, pulmonary, metabolic, autoimmune and neoplastic diseases. Int J Biochem Cell Biol 2009;41:40-59.

10. Zhao X, Xu Y, Zhao Q, Chen CR, Liu AM, Huang ZL. Curcumin exerts antinociceptive effects in a mouse model of neuropathic pain: Descending monoamine system and opioid receptors are differentially involved. Neuropharmacology 2012;62:843-54.

11. Jain K, Sood S, Gowthamarajan K. Modulation of cerebral malaria by curcumin as an adjunctive therapy. Braz J Infect Dis 2013;17:579-91.

12. Mendonça LM, da Silva Machado C, Teixeira CC, de Freitas LA, Bianchi MD, Antunes LM. Curcumin reduces cisplatin-induced neurotoxicity in NGF-differentiated PC12 cells. Neurotoxicology 2013;34:205-11.

13. Abbas SH, Abdulridha MK, Najeb AA. Potential benefit of curcumin adjuvant therapy to the standard helicobacter pylori eradication therapy in patients with peptic ulcer disease. Asian J Pharm Clin Res 2017;10:313-7.

14. Srinivasan M. Curcumin, a potent anticarcinogenic polyphenol - A review. Asian J Pharm Clin Res 2014;7:1-8.

15. Mohanty C, Das M, Sahoo SK. Emerging role of nanocarriers to increase the solubility and bioavailability of curcumin. Expert Opin Drug Deliv 2012;9:1347-64.

16. Patel K, Padhye S, Nagarsenker M. Duloxetine HCl lipid nanoparticles: Preparation, characterization, and dosage form design. AAPS PharmSciTech 2012;13:125-33.

17. Young NA, Bruss MS, Gardner M, Willis WL, Mo X, Valiente GR, et al. Oral administration of nano-emulsion curcumin in mice suppresses inflammatory-induced NFKB signaling and macrophage migration. PLoS One 2014;9:e111559.

18. Ray B, Bisht S, Maitra A, Maitra A, Lahiri DK. Neuroprotective and neurorescue effects of a novel polymeric nanoparticle formulation of curcumin (NanoCurc ${ }^{\mathrm{TM}}$ ) in the neuronal cell culture and animal model: Implications for Alzheimer's disease. J Alzheimer's Dis 2011;23:61-77.

19. Setia A, Kansal S, Goyal N. Development and optimization of enteric coated mucoadhesive microspheres of duloxetine hydrochloride using 32 full factorial design. Int J Pharm Invest 2013;3:141.

20. Shah R, Zidan A, Funck T, Tawakkul M, Nguyenpho A, Khan M. Quality by design: Characterization of self-nano-emulsified drug delivery systems (SNEDDs) using ultrasonic resonator technology. Int J Pharm 2007;341:189-94.

21. Sheladia S, Patel B. Implementation of QBD approach to develop and validate analytical method for simultaneous estimation of duloxetine hydrochloride and methylcobalamin in pharmaceutical dosage form by HPTLC method. Int J Pharm Pharm Sci 2016;9:105-13. 
22. Khan AA, Mudassir J, Mohtar N, Darwis Y. Advanced drug delivery to the lymphatic system: Lipid-based nanoformulations. Int J Nanomed 2013;8:2733.

23. Mohanraj V, Chen Y. Nanoparticles-a review. Trop J Pharm Res 2006;5:561-73

24. Kang JH, Oh DH, Oh YK, Yong CS, Choi HG. Effects of solid carriers on the crystalline properties, dissolution and bioavailability of flurbiprofen in solid self-nanoemulsifying drug delivery system (solid SNEDDS). Eur J Pharm Biopharm 2012;80:289-97.

25. Date AA, Nagarsenker M. Design and evaluation of selfnanoemulsifying drug delivery systems (SNEDDS) for cefpodoxime proxetil. Int J Pharm 2007;329:166-72.

26. Desai N, Nagarsenker M. Design and evaluation of self-nanoemulsifying pellets of repaglinide. AAPS PharmSciTech 2013;14:994-1003.

27. Kumar B, Garg V, Singh S, Pandey NK, Bhatia A, Prakash T, et al. Impact of spray drying over conventional surface adsorption technique for improvement in micromeritic and biopharmaceutical characteristics of self-nanoemulsifying powder loaded with two lipophilic as well as gastrointestinal labile drugs. Powder Technol 2017;326:425-42.

28. Kumar B, Malik AH, Sharma P, Rathee H, Prakash T, Bhatia A, et al. Validated reversed-phase high-performance liquid chromatography method for simultaneous estimation of curcumin and duloxetine hydrochloride in tablet and self-nanoemulsifying drug delivery systems. J Pharm Res 2017;11:1166.

29. Sood S, Jain K, Gowthamarajan K. Optimization of curcumin nanoemulsion for intranasal delivery using design of experiment and its toxicity assessment. Colloid Surfaces B Biointerfaces 2014;113:330-7.

30. Shah VP, Tsong Y, Sathe P, Liu JP. In vitro dissolution profile comparison - Statistics and analysis of the similarity factor, f2. Pharm Res 1998;15:889-96.

31. Singare DS, Marella S, Gowthamrajan K, Kulkarni GT, Vooturi R, Rao PS, et al. Optimization of formulation and process variable of nanosuspension: An industrial perspective. Int $\mathrm{J}$ Pharm 2010;402:213-20. 